\title{
Full Paper Epidemiology and pathophysiology of cancer-associated thrombosis
}

\author{
S Noble ${ }^{*, 1}$ and J Pasi ${ }^{2}$ \\ 'Royal Gwent Hospital, Cardiff Road, Newport NP202UB, UK; '²Centre for Haematology Institute of Cell and Molecular Science, Barts and The London \\ School of Medicine and Dentistry, 4 Newark Street, London EI 2AT, UK
}

\begin{abstract}
Venous thromboembolism (VTE) is a common complication in patients with malignant disease. First recognised by Bouillard in 1823 and later described by Trousseau in 1844, multiple studies have since provided considerable evidence for a clinical association between VTE and cancer. Across all cancers, the risk for VTE is elevated 7-fold; in certain malignancies, the risk for VTE may be increased up to 28-fold. Venous thromboembolism is the second leading cause of death in patients with cancer; among survivors, complications commonly include recurrent VTE and post-thrombotic syndrome, and (more rarely) chronic thromboembolic pulmonary hypertension, which are costly, and have a profound impact on the patient's quality of life. Tumour cells can activate blood coagulation through multiple mechanisms, including production of procoagulant, fibrinolytic, and proaggregating activities, release of proinflammatory and proangiogenic cytokines, and interacting directly with host vascular and blood cells (e.g., endothelial cells, leukocytes, and platelets) through adhesion molecules. Increasing evidence suggests that elements of the haemostatic system also have a direct role in eliciting or enhancing angiogenesis, cell survival, and metastasis. Despite the problem posed by VTE in the setting of cancer, it is evident that a significant number of oncologists do not recognise the link between cancer, its treatment, and thrombogenesis. On 22 May 2009, a group of UK-based physicians met in London, UK, to evaluate recent data on cancer thrombosis. This article (I of 4) briefly reviews key data on the epidemiology and pathophysiology of VTE as a context for a discussion and consensus statement developed by meeting attendees, on the implications of this information for UK clinical practice.

British Journal of Cancer (2010) I 02, S2-S9. doi:I0.1038/sj.bjc.6605599 www.bjcancer.com
\end{abstract}

(c) 2010 Cancer Research UK

Keywords: venous thromboembolism; thrombosis; epidemiology

The relationship between cancer and venous thromboembolism (VTE) has been recognised for almost two centuries. Historically, the French physician, Armand Trousseau, is credited with initially describing the relationship between VTE and cancer in a seminal book published in 1865 (Trousseau, 1865); however, it has since been recognised that the first description of deep vein thrombosis (DVT) in patients with cancer was made by Bouillard in 1823-42 years earlier than Trousseau (Bouillard and Bouillaud, 1823). Since the time of Bouillard and Trousseau, multiple studies have provided considerable evidence for a two-way clinical association between VTE and cancer: contemporary studies, such as the 2005 MEGA (Multiple Environmental and Genetic Assessment) study, clearly indicate that patients with cancer have an elevated risk for VTE, particularly during the first few months after diagnosis and in the presence of distant metastases (Blom et al, 2005). Conversely, the risk for cancer seems elevated for at least 2 years after a first episode of idiopathic VTE (Murchison et al, 2004).

Cancer is responsible for $18 \%$ of all cases of incident VTE. Across all patients with cancer, the risk for VTE is elevated 7-fold; in certain malignancies, the risk for VTE may be increased up to 28 -fold (Blom et al, 2005). In patients with cancer, VTE is the second leading cause of death; in fact, of every seven patients with cancer who die while hospitalised, one will die of pulmonary

*Correspondence: Dr S Noble; E-mail: simon.noble@gwent.wales.nhs.uk embolism (PE). Even among patients who survive an episode of VTE, complications such as recurrent VTE, post-thrombotic syndrome, and chronic thromboembolic pulmonary hypertension are common, costly, and have a profound impact on the patient's quality of life.

Despite the problem posed by VTE in the setting of cancer, it is evident that a notable proportion of oncologists do not recognise the link between cancer, its treatment, and thrombogenesis. Moreover, many do not recognise the need for thromboprophylaxis in selected patient populations. A small 2003 questionnaire survey, conducted in northern England, examined prophylaxis for VTE during treatment for cancer (Kirwan et al, 2003). Among oncologists who responded, over $27 \%$ believed that their patients were not at risk for VTE. This response was independent of the type of tumour treated (Kirwan et al, 2003). It is noteworthy that over $60 \%$ of respondents did not believe that hormone therapy or chemotherapy increased risk for VTE (Kirwan et al, 2003), and approximately $80 \%$ did not use thromboprophylaxis routines in chemotherapy or hormone therapy. Similarly, the FRONTLINE survey - a comprehensive global survey of thrombosis and cancer - found that $50 \%$ of surgical cancer patients and $95 \%$ of medical patients do not use thromboprophylaxis (Kakkar et al, 2003).

On 22 May 2009, a small group of UK-based health-care providers gathered in London, UK, to evaluate the most recent data on cancer-associated thrombosis and its implications for UK clinical practice. This article -1 of 4 covering broad topics in 
cancer thrombosis - includes a brief review of key data on the epidemiology and pathophysiology of VTE to provide context for a discussion surrounding these data and a consensus statement, developed by meeting attendees, on the implications of this information for UK clinical practice.

\section{THE RISK FOR DVT AND PE IN PATIENTS WITH CANCER}

A large, population-based, case-control study - the MEGA study found that patients with cancer have a significantly increased risk for VTE, particularly during the first few months after diagnosis and in the presence of distant metastases (Blom et al, 2005). Among the cohort examined in this study, which comprised over 3200 patients with a first DVT of the leg, PE, or both, the overall risk for VTE was elevated by 7 -fold in patients, compared with a malignancy (Blom et al, 2005), with the most profound increases in risk seen in patients with haematological malignancies (28-fold increased risk), lung cancer (22-fold), gastrointestinal cancer (20-fold), or with distant metastases (19.8-fold) (Blom et al, 2005). The risk for VTE was 54-fold higher from 0 to 3 months after diagnosis, rapidly declining thereafter to 14 -fold higher at 3-12 months and 3.6 at 1-3 years after diagnosis. Notably, however, the risk for VTE remained appreciably elevated up to 15 years after initial diagnosis (Blom et al, 2005).

Epidemiological studies suggest that haematological, lung, and gastrointestinal cancers, as broad diagnostic categories, are associated with a substantial risk for VTE. Significant efforts have been made to further delineate the cancer types that are associated with the highest risk for thrombotic events. In 1999, Levitan and colleagues assessed the rate of DVT/PE in a population of $>1.2$ million US Medicare patients (primarily aged $\geqslant 65$ years) initially admitted with a malignancy (Levitan et al, 1999). As shown in Table 1, malignancies associated with the highest incidence of DVT/PE include kidney, stomach, pancreas, brain, and ovarian, as well as lymphoma. In contrast, cancers of the head and neck, bladder, breast, oesophagus, uterus, and cervix are associated with relatively low rates of DVT/PE.

The incidence of VTE in hospitalised patients with cancer increased sharply between 1979 and 1999 (Figure 1) (Stein et al, 2006). This increase has been substantially sharper than the rise in incidence observed among hospitalised patients who do not have cancer. These data suggest that improved diagnostic modalities are only partly responsible for changes over time in the incidence of VTE in patients with malignancies. Similarly, Khorana et al (2006) found that there was a $36 \%$ increase in venous events among hospitalised neutropenic cancer patients between 1995 and 2002 .

The data summarised above clearly indicate that the risk for VTE is elevated appreciably in patients with cancer. Data also suggest that patients with cancer undergoing surgical procedures have an approximately two-fold increased risk for developing VTE compared with those without cancer (White et al, 2005).

\section{Impact of cancer therapy}

Cancer therapy itself has been shown to increase the risk for VTE, whether it be chemotherapy, antiangiogenic therapy, or hormonal therapy. With regard to chemotherapy, Blom et al (2004) conducted a prospective, multicentre, observational study in which the overall incidence of VTE in an ambulatory population starting a new chemotherapy was $1.93 \%$ over a median follow-up period of 2.4 months. The rate of VTE observed in this study $(0.8 \%$ per month) was substantially in excess of the estimated rate of approximately $0.04 \%$ per month for the entire cancer population. As noted earlier, lung cancer is associated with a 20 -fold increased risk for thrombosis. Data suggest that chemotherapy is associated
Table I Rates of DVT/PE in different malignancies

\begin{tabular}{|c|c|}
\hline Site & $\begin{array}{c}\text { Rate of DVT/PE per } \\
10000 \text { patients }\end{array}$ \\
\hline Head/neck & 16 \\
\hline Bladder & 22 \\
\hline Breast & 22 \\
\hline Oesophagus & 43 \\
\hline Uterus & 44 \\
\hline Cervix & 49 \\
\hline Prostate & 55 \\
\hline Lung & 61 \\
\hline Rectal & 62 \\
\hline Liver & 69 \\
\hline Colon & 76 \\
\hline Leukaemia & 81 \\
\hline Renal & 84 \\
\hline Stomach & 85 \\
\hline Lymphoma & 96 \\
\hline Pancreas & 110 \\
\hline Brain & 117 \\
\hline Ovary & 120 \\
\hline
\end{tabular}

An analysis of $>1.2$ million US Medicare (age $\geqslant 65$ ) patients admitted to the hospital with a malignancy (Levitan et al, 1999).

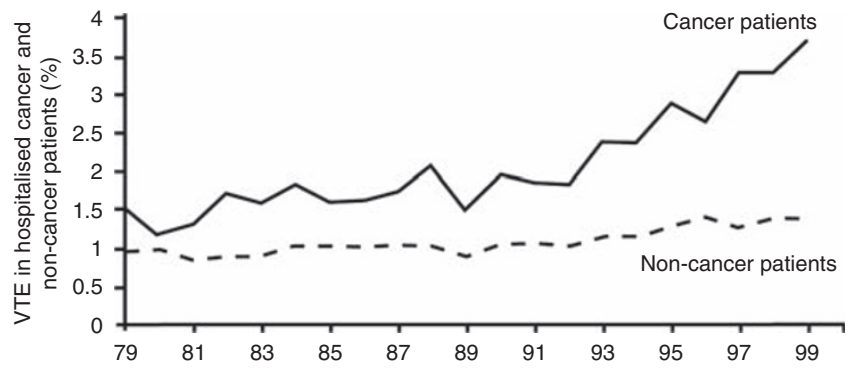

Figure I Increased VTE prevalence over time in patients with cancer, but not in those without cancer (Stein et al, 2006).

with a three-fold increased risk for VTE over and above this already elevated rate, with further increases with time on chemotherapy (Blom et al, 2004).

\section{Antiangiogenic chemotherapy}

Antiangiogenic therapies can have significant effects on VTE incidence. When used alone, the rate of VTE among thalidomide patients is $<2 \%$. However, when combined with dexamethasone or other chemotherapies, the rate of VTE increases to $12-26 \%$ (Barlogie et al, 2001; Zangari et al, 2001; Cavo et al, 2002; Rajkumar et al, 2006). Some data indicate that lenalidomide may be associated with a somewhat lower incidence of VTE, particularly when combined with aspirin (Rajkumar et al, 2006). Some early data suggested that the monoclonal antibody, bevacizumab, may be associated with increased risk for VTE (Shah et al, 2005); some recent trials indicate that bevacizumab in the context of contemporary chemotherapy regimens is not associated with significant elevations in risk (Hurwitz et al, 2004). In contrast, a more recent meta-analysis of 15 trials conducted in patients with advanced solid tumours $(N=7956)$ found that the overall incidence of all-grade and high-grade VTE was 11.9 and $6.3 \%$, respectively (Nalluri et al, 2008). Patients who received bevacizumab in these trials had a significantly increased risk for VTE, with a relative risk of 1.33. Risk for VTE was not dose dependent: at a low bevacizumab dosage of $2.5 \mathrm{mg} \mathrm{kg}^{-1}$ per week, the relative risk for VTE was $1.31(P=0.007)$; at a high dosage of 
$5.0 \mathrm{mg} \mathrm{kg}^{-1}$ per week, the relative risk was identical at 1.31 $(P=0.04)$.

\section{Hormonal therapy}

Adjuvant hormonal therapy with tamoxifen is also recognised to increase the risk for VTE (Saphner et al, 1991). In a study on 2600 patients with breast cancer enrolled in the Eastern Cooperative Oncology Group adjuvant studies, the frequency of venous and arterial thrombosis was significantly higher among adjuvant therapy patients compared with observation-only patients $(5.4 \mathrm{vs}$ $1.6 \%$; $P=0.0002$ ). Notably, the risk for VTE seems to be reduced with aromatase inhibitors compared with tamoxifen (Howell et al, 2005). In the Arimidex, Tamoxifen alone, or in Combination (ATAC) study, the rate of VTE after 68 months of follow-up was $4.5 \%$ in patients who received tamoxifen, compared with $2.8 \%$ in those who received anastrozole.

\section{Erythropoietin-stimulating agents}

A systematic review of randomised trials suggests that these agents (e.g., epoetin $\alpha$ and $\beta$; darbepoetin $\alpha$ ) are associated with an approximately $67 \%$ increased risk for VTE (Bohlius et al, 2006).

\section{Mode of administration}

Central venous catheters, in the form of surgically tunnelled catheters or totally implanted venous access devices, are being increasingly used in clinical practice. Although these devices have revolutionised the clinical management of patients with cancer, they are associated with considerable morbidity, occasional mortality, and the loss of catheters. Indwelling catheters have been shown to be associated with a $27-67 \%$ incidence of catheterassociated DVT, which is primarily asymptomatic (Monreal et al, 1994; Prandoni et al, 1997a; Verso and Agnelli, 2003). Pulmonary embolism is observed in $15-36 \%$ of patients with symptomatic catheter-associated DVT. The wide variability in the incidence of catheter-related thrombosis may be due to differences in catheter type, position, duration of insertion, type of malignancy, and use of different chemotherapeutic agents. It is important to note that because catheters are deep in the mediastinum - thrombosis is frequently not discovered until late in its course, magnifying the consequences of DVT in these patients and complicating treatment considerably.

\section{CONSEQUENCES OF DVT AND PE}

Venous thromboembolism is associated with considerable mortality. Khorana et al (2006) estimated the incidence of VTE in hospitalised cancer patients actively receiving therapy. In-hospital mortality was substantially higher among patients with VTE compared with patients without such a diagnosis $(\mathrm{OR}=2.01$; $P<0.0001$ ), with a somewhat greater risk for death among patients with metastatic disease $(\mathrm{OR}=2.06 ; P<0.0001)$ than in those with non-metastatic disease $(\mathrm{OR}=1.62 ; P<0.0001)$.

The @RISTOS project prospectively examined the epidemiology of VTE after cancer surgery. In this study, patients were assessed for clinically overt VTE occurring up to $30 \pm 5$ days (or more if the hospital stay was $>35$ days) (Agnelli et al, 2006). Among the total population of 2373 patients who underwent surgery, the overall death rate was $1.72 \%$. Of these, death was caused by VTE in nearly half $(46.3 \%)$ of the cases, making it the most common single cause of death at 30 days after surgery.

Beyond mortality, VTE is associated with a number of conditions that can severely compromise patients' quality of life and add tremendously to the burden attributable to this condition, including recurrent VTE, post-thrombotic syndrome, and pulmonary hypertension.

\section{Recurrent VTE and bleeding}

Venous thromboembolism is now considered to be a chronic disease, in that the risk for recurrence persists for many years after the initial event. A prospective follow-up study, conducted by Prandoni and colleagues and published in 2002, evaluated the risk for recurrent VTE or bleeding during anticoagulant treatment in 842 patients with DVT with and without cancer who were receiving anticoagulant therapy (Prandoni et al, 2002). Among the 181 patients included in the study who had known cancer at study entry, the cumulative incidence of recurrent VTE was $20.7 \%$, compared with $6.8 \%$ among those without cancer (hazard ratio 3.2; Figure 2A). The incidence of major bleeding was also increased 2.2-fold among patients with cancer (12.4 vs 4.9\%) (Figure 2B). Both recurrence and bleeding were related to cancer severity, occurred primarily during the first month of anticoagulant therapy, and were not adequately explained by over- or undercoagulation. These data suggest that many patients with cancer with an initial episode of VTE may require extended - and sometimes lifelong - antithrombotic therapy; however, the risks for bleeding must be carefully weighed against the thromboprophylactic benefit associated with treatment, and patients must be closely monitored for symptoms of bleeding, even when in the therapeutic range for a given anticoagulant.

\section{Post-thrombotic syndrome}

Few data are available on the incidence of post-thrombotic syndrome in patients with cancer; however, approximately $30 \%$ of patients with DVT overall subsequently develop this chronic, frequently disabling condition within 5 years of an incident, of whom $8.1 \%$ will have severe post-thrombotic manifestations (Prandoni et al, 1997b). Symptoms of post-thrombotic syndrome include debilitating leg pain, swelling, and fibrosis. Severe manifestations may result in leg ulceration, limitation in mobility, and the need for long-term nursing care.

\section{Pulmonary hypertension}

Pulmonary hypertension is a life-threatening condition associated with fatigue, chest pain, peripheral swelling, and increased mortality. Recent studies suggest that $4-5 \%$ of patients develop pulmonary hypertension $\leqslant 2$ years after symptomatic PE (Pengo et al, 2004).

\section{THE PATHOPHYSIOLOGY OF VTE IN CANCER}

\section{Overview of the haemostatic system}

The haemostatic system is a complex, multifaceted host defence mechanism that evolved to protect the integrity of the vascular system. It works in coordination with the mechanisms of inflammation and repair, producing a coordinated response. Haemostatic systems are normally quiescent and are only activated after injury. Ultimately, the coordinated haemostatic response results in the production of a platelet plug, fibrin-based clot, deposition of white cells at the point of injury, and activation of inflammatory and repair processes.

After injury and vessel vasoconstriction, reduced blood flow permits contact activation of platelets (Figure 3). Subsequently, platelets adhere to exposed connective tissue (mediated in part by the von Willebrand factor) and release an array of vasoactive proteins that interact with other platelets and leukocytes, enhancing platelet activation and leading to the formation of 

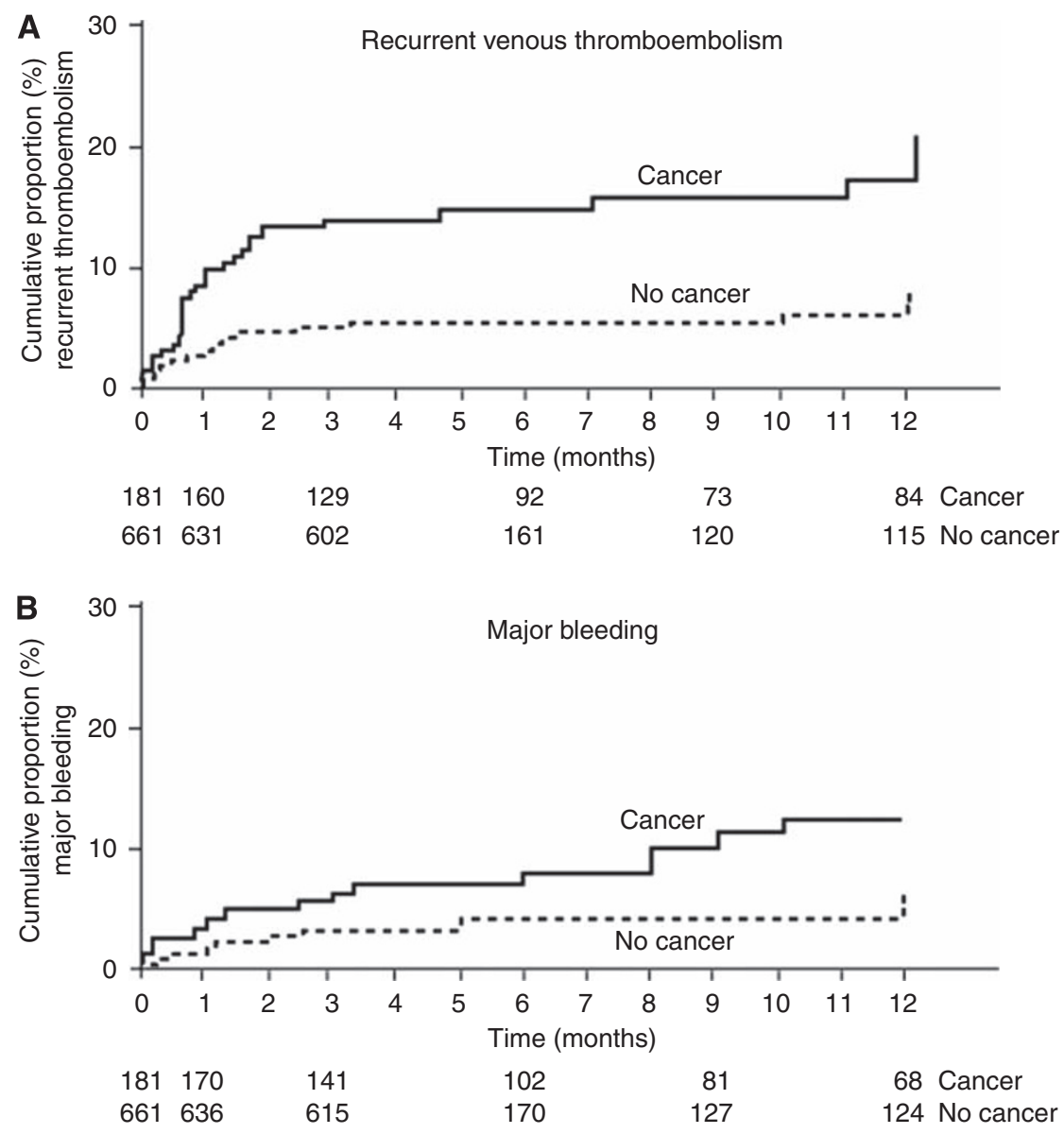

Figure 2 (A) Cumulative incidence of recurrent VTE during anticoagulant therapy among patients with and without cancer. (B) Cumulative incidence of bleeding during anticoagulant therapy among patients with and without cancer (Prandoni et al, 2002).

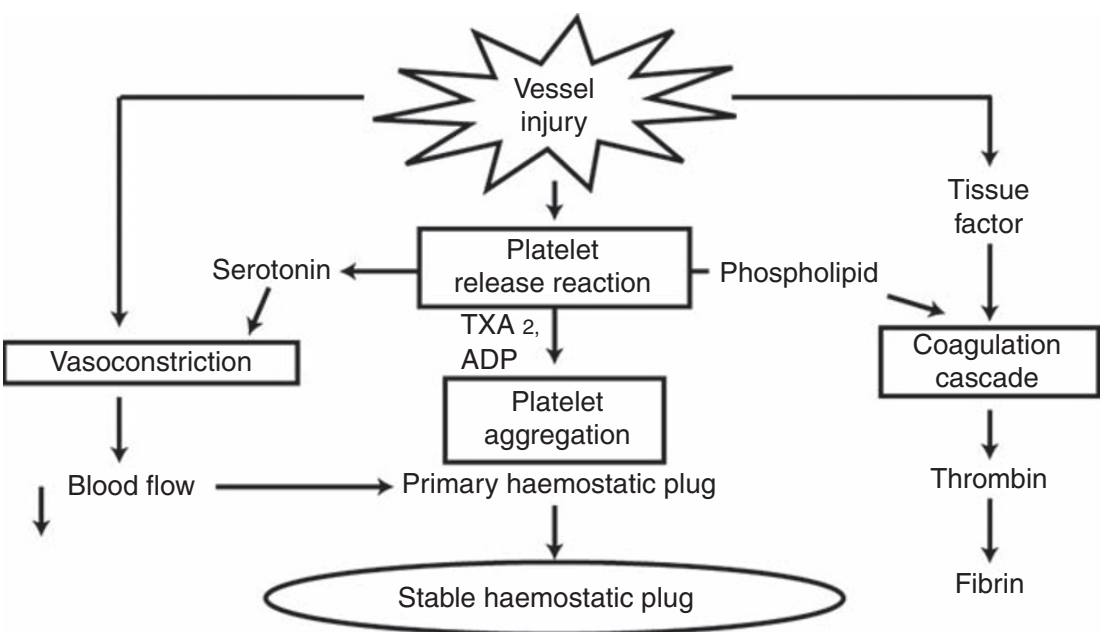

Figure 3 A simplified overview of the haemostatic cascade (Colman, 2006).

platelet aggregates to form the initial platelet plug. At the same time, the vascular endothelium moves from its resting phase (anticoagulant) to a more active (procoagulant) and repair phase. In concert with these cellular changes, inactive plasma coagulation factors are converted to their respective active species by cleavage at internal peptide bonds. In sequence, these active factors generate thrombin, which leads to the formation of fibrin from fibrinogen (to stabilise the platelet plug), cross-linking of fibrin (through activation of factor XIII), further activation of platelets, and activation of fibrinolytic pathways (to enable plasmin to dissolve fibrin strands in the course of wound healing). In addition, thrombin interacts with other non-haemostatic systems to promote cellular chemotaxis, fibroblast growth, angiogenesis, and wound repair. 


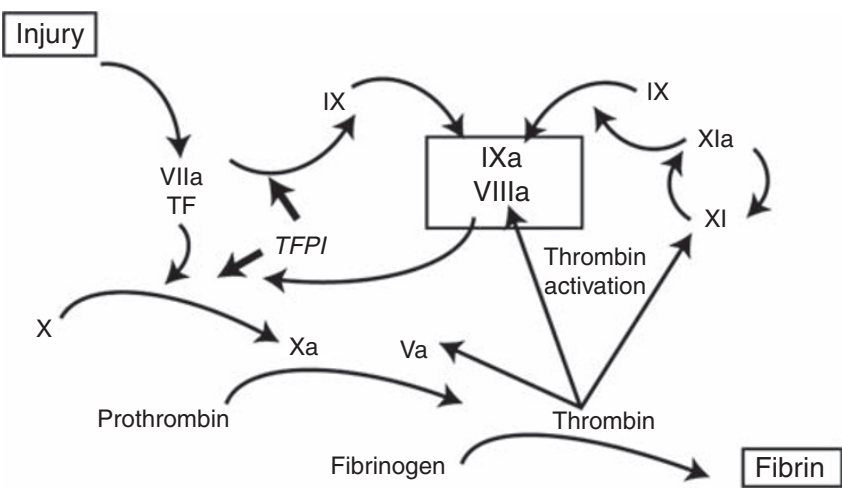

Figure 4 The coagulation cascade (Colman, 2006).

A simplified overview of the coagulation cascade is shown in Figure 4 (Colman, 2006). The major role of the coagulation cascade is the production of fibrin - the meshwork that holds together the clot - which is produced through a cleavage of fibrinogen by thrombin. Coagulation is initiated by tissue damage, exposing the transmembrane glycoprotein tissue factor (TF). Tissue factor is expressed on the subendothelial surface of blood vessels and is normally exposed only when normal vasculature is disrupted. Factor VII binds TF, and the TF-factor VII complex directly activates factor X to factor Xa and some factor IX to factor IXa. In the presence of factor Xa, tissue factor pathway inhibitor (TFPI) inhibits further generation of factor $\mathrm{Xa}$ and factor IXa. After inhibition by TFPI, the amount of factor $\mathrm{Xa}$ produced is insufficient to maintain coagulation. Additional factor $\mathrm{Xa}$ (which allows haemostasis to progress to completion) can only be generated by the factor IX - factor VIII pathway. Enough thrombin exists at this point to activate factor VIII, and together with factor IXa (generated by TF-factor VIIa) to further activate factor X. Factor IX activation is also augmented by thrombin activation of the factor XI pathway. Without the amplification and consolidating action of factor VIII/factor IX, there is insufficient generation of factor $\mathrm{Xa}$ to produce sufficient thrombin. When sufficient thrombin is generated, this endolytic serine protease selectively cleaves the Arg-Gly bonds of fibrinogen to form fibrin, releasing fibrinopeptides A and B and so forms the meshwork of the clot.

It is of note that the above physiological description omits the classic extrinsic pathway (factor VII-TF initiated coagulation to common pathway at factor $\mathrm{X}$ ) and intrinsic pathways activated by factor XII (and through factors XI, IX, and VIII to common pathway at factor X). Although factor XII has no role in physiological blood coagulation, it has been considered that it may have a role in cancer-related thrombosis (see below). Indeed most, if not all, aspects of the complex integrated haemostatic system have been considered to function pathologically in the setting of cancer.

\section{Activation of the haemostatic system in cancer}

Multiple pathways are responsible for regulating cancer growth, progression, and metastasis. Tumour cells (both solid and haematological) can activate blood coagulation through multiple mechanisms, including production of procoagulant, fibrinolytic, and proaggregating activities; release of proinflammatory and proangiogenic cytokines; and direct interaction with host vascular and blood cells (e.g., endothelial cells, leukocytes, and platelets) through adhesion molecules. The link between the haemostatic system and cancer is shown by a study conducted by Miller et al (2004), which evaluated haemostatic status every year for 4 years in a population of approximately 3000 middle-aged men without cancer. Among patients with the activation of the haemostatic
Table 2 Changes in haemostasis due to malignancy

\begin{tabular}{ll}
\hline $\begin{array}{l}\text { Changes that increase } \\
\text { bleeding }\end{array}$ & Changes that increase thrombosis \\
\hline $\begin{array}{l}\text { Platelet dysfunction } \\
\text { Dysproteinemias }\end{array}$ & $\begin{array}{l}\text { Platelet activation } \\
\text { Direct factor } X \text { activation by TF and other } \\
\text { proteases } \\
\text { Reduced hepatic anticoagulant synthesis }\end{array}$ \\
$\begin{array}{l}\text { Thrombocytopenia } \\
\text { Reduced hepatic clotting } \\
\text { factor synthesis }\end{array}$ & $\begin{array}{l}\text { Decreased hepatic clearance of activated factors } \\
\text { Isolated factor defects }\end{array}$ \\
$\begin{array}{l}\text { Autoimmune phenomena } \\
\text { (e.g., inhibitors) }\end{array}$ & $\begin{array}{l}\text { Autoimmune phenomena (e.g., lupus } \\
\text { anticoagulant (APL)) }\end{array}$ \\
\hline
\end{tabular}

Adapted from Hoffman et al (200I).

system (defined as persistent elevation of fibrinopeptide A and prothrombin fragment $1+2$ levels), total mortality was substantially higher in participants with persistent activation $(17.1 / 1000$ person-years) than in patients without activation (9.7/1000 personyears; $P=0.015)$. This difference was attributable to an increased incidence of death from cancers $(11.3 / 1000$ vs 5.1/1000 personyears), primarily due to a three-fold higher mortality from cancers of the digestive tract (6.3/1000 vs 1.9/1000 person-years).

The majority of patients with cancer has increased levels of coagulation factors V, VIII, IX, and XI, as well as increased levels of markers of coagulation activation (e.g., thrombin-antithrombin, prothrombin fragment $1+2$, fibrinopeptide, and D-dimer (Table 2) (Hoffman et al, 2001). In addition, patients with disseminated malignancies seem to have a deficient activity of von Willebrand's factor-cleaving protease (ADAMTS13), resulting in unusually large von Willebrand factor multimers, a key adhesive protein involved in primary haemostasis (Oleksowicz et al, 1999).

Many tumours have been shown to activate blood coagulation through an abnormal expression of high levels of the procoagulant molecule TF. In normal vascular cells, expression of TF is normally not expressed, except when induced by inflammatory cytokines such as interleukin $1 \beta$ and tumour necrosis factor $\alpha$ (TNF- $\alpha$ ) or by bacterial lipopolysaccharides. In tumour cells, TF is expressed constitutively. Constitutive activation of the extrinsic pathway has been shown in patients with cancer. In a study conducted by Kakkar et al (1995), plasma levels of TF, factor VIIa, factor XIIa, the thrombin - antithrombin complex, and prothrombin fragments were elevated in patients with cancer compared with healthy controls. Tissue factor and factor VIIa levels were both significantly higher, suggesting that the extrinsic pathway was strongly activated. Levels of factor XIIa were only slightly elevated, suggesting that the intrinsic pathway is not involved to a significant extent in the hypercoagulable state seen in patients with cancer (Rickles and Brenner, 2008).

Tumour cells express cancer procoagulant, a cysteine protease expressed only on malignant tissue. Cancer procoagulant directly activates factor X independently of factor VII (Falanga and Gordon, 1985). Its activity seems to be driven by the stage of cancer, in that onset of disease is associated with high levels of activity that slowly declines thereafter (Mielicki et al, 1999).

In addition to the expression of $\mathrm{TF}$ and cancer procoagulant, tumour cells enhance coagulation in patients with cancer by expressing proteins that regulate the fibrinolytic system, including plasminogen activators, plasminogen activator inhibitors 1 and 2, and plasminogen-activator receptor, leading to an imbalance of fibrinolysis (Prandoni et al, 2005). Tumour cells may elicit platelet activation and aggregation through direct cell-cell interactions or through the release of soluble mediators, including ADP, thrombin, and other proteases. Furthermore, expression of certain cytokines by tumour cells, including TNF- $\alpha$ and interleukin $1 \beta$, 
induces expression of TF on endothelial cells and simultaneously downregulates the expression of thrombomodulin, resulting in a prothrombotic milieu at the vascular wall (because of reduced protein-C activation).

As noted in the Introduction, multiple studies have provided considerable evidence for a two-way clinical association between VTE and cancer, in that cancer elicits expression of procoagulant activities, contributing to the prothrombotic state in these patients, and the procoagulant activities themselves seem to elicit cancer growth, proliferation, and metastasis. Fibrin and platelet deposition around solid tumours promotes angiogenesis through platelet-derived proangiogenic factors, and may seal immature tumour vasculature and provide a degree of immunological 'invisibility'. Fibrin has been shown to induce expression of IL-8 and VEGF - thereby enhancing angiogenesis - and to increase expression of TF (Qi and Kreutzer, 1995; Fernandez et al, 2004). The TF-factor VIIa complex can signal through cleavage of protease-activated receptors, which in turn induce the mitogenactivated protein kinase (MAPK) signal transduction cascade (Rao and Pendurthi, 2005). The MAPK pathway, in turn, is involved in the induction of genes involved in angiogenesis, migration, and proliferation. In addition, phosphorylation of the cytoplasmic tail of the TF receptor has also been shown to indirectly activate transcription of VEGF, downregulate thrombospondin (an antiangiogenic protein), and induce cell migration. Expression of TF by malignant cells also seems to support metastatic success and is dependent on the formation of the TF-factor VIIa complex.

\section{DISCUSSION}

Faculty: A major question is whether the poor survival in patients is due to more aggressive tumours or whether it is mortality due to thrombotic events.

John Pasi: Absolutely. It is likely to be both. The data we have now are superficial, in that they do not separate these 2 factors.

Faculty: Are the mechanisms underlying VTE similar across all tumour types? Is there a difference between how gastrointestinal malignancies activate haemostatic pathways compared with breast cancer?

John Pasi: Different elements are expressed in different tissues. Some of the broad mechanisms are going to be common across all tumour types. Haematological malignancies are clearly different in the way that they induce thrombosis. I suspect that there will be broad common themes, but there will be a different emphasis on elements of the coagulation system across tumours.

Faculty: There are some data suggesting that different histological types of lung cancer - for example, adenocarcinomas - are more strongly associated with VTE.

John Pasi: Yes, some of the metastatic non-small-cell lung cancers produce large amounts of TF, which will drive the coagulation process in this case.

Faculty: The rates of thromboembolism clearly vary among tumour types and histologies. This is explained partly by the ability of the tumour to generate procoagulants and partly by host factors. As much as the risk for thromboembolism is driven by the tumour itself, there are features of the individual patient that drive risk for VTE. For example, patients who are more debilitated will be less mobile or the anatomical site of the tumour may compress great veins. The interaction between these and other factors will determine risk for VTE.

Faculty: Is there a scoring system that can be applied?

Faculty: A validated scale is not available. One scoring system has been derived from the Neupogen registry. There was a retrospective analysis of this scoring system, which scored tumours by site, platelet count, haemoglobin, and other risk factors. If the score was 0,1 , or 2 , the risk of VTE in the first 3 cycles of chemotherapy was very low. If the score was 3 or greater, the risk for VTE during early cycles was approximately $7 \%$. The problem with this scoring system is that it only measures risk in a very specific patient population - one that was quite unwell and immobile.

Faculty: Many oncologists do not systematically search for thrombosis. There is the possibility that if an effort is made to screen patients extensively for thrombosis, more will be found and patients may receive unwarranted treatment. If you take 100 cancer patients and you screen them extensively for thrombosis, what would you find?

John Pasi: I believe we do not have precise estimates in patients with cancer, but anecdotally, we frequently see asymptomatic emboli when patients are undergoing CT or other diagnostic procedures.

Faculty: We do not know if these incidental thrombi will influence outcomes.

John Pasi: But you can suggest that the incidental finding of thrombus may predict recurrence, therefore identifying patients at risk.

Faculty: I think that is an interesting question. Are those incidental thrombi truly asymptomatic? There is some work in the United States that suggests that about $60 \%$ of patients in whom you find an incidental pulmonary embolus will have symptoms of pulmonary emboli, if questioned carefully. These symptoms may be masked by the underlying cancer or its treatment, or the fact that these patients are not active.

Faculty: Is it worthwhile to treat asymptomatic emboli?

John Pasi: It depends on how you extrapolate the data. If you extrapolate the data that symptomatic presentation is associated with a higher rate of recurrence, asymptomatic presentation could equally be associated with significant rate of recurrence. And therefore, you could argue that it is worth treating it. The question is whether there is any evidence for treating asymptomatic emboli - it would make for an interesting study.

Faculty: The problem is that treatment increases the risk for major bleeding. The risk of major bleeding, even with 6 months of anticoagulation, is approximately $5 \%$, and this is associated with a substantial risk for death. If the pulmonary embolism has no symptoms and we treat it, we will be causing harm in a certain number of patients. I do not think this is an issue that will be solved without further study, but for now I believe that the correct assumption is they should be treated, with the strong caution that there is a lack of evidence.

Faculty: As an oncologist, are you identifying more venous thrombosis than you were earlier in your career?

Faculty: Yes.

Faculty: Is that because of diagnostic advances as opposed to a true increase in the rate of VTE?

Faculty: Lung cancer patients have symptoms that are similar to $\mathrm{PE}$, so in many cases symptoms will be masked. In the past, only a small percentage of lung cancer patients received a CT scan. Now, almost all receive a CT scan. So of course you will pick up more PE.

Faculty: I think that's right. The general consensus is that 64-slice CT scanning is probably the biggest reason for identifying more thrombosis in cancer patients. If you go to historic postmortem series from the 1930s, for instance, there was a huge incidence of thrombosis. And if you're looking at a series in the 1960s and 1970s in Scandinavia, between 30 and $60 \%$ of patients with malignant disease had evidence of pulmonary embolism at the time of death. Whether that was contributory or the main cause of death or whether it contributed to death is not entirely clear. The question is, on a relative basis, how important is VTE in cancer patients? I think it probably is important, but data are lacking.

\section{CONSENSUS STATEMENT}

Venous thromboembolism is a common occurrence within the cancer population, and the thrombotic risk due to the tumour itself 
is further increased by cancer therapies such as chemotherapy and surgery. However, the cancer population is markedly heterogeneous, with a broad array of histologies, stages, and therapeutic interventions. Consequently, the risk for VTE varies among patients with cancer. Thus, priority should be placed on the development of a cancer-specific risk assessment tool to identify those who would benefit most from thromboprophylaxis. There is very little evidence to inform the use of thromboprophylaxis in the ambulant, nonhospitalised cancer patients, particularly those receiving chemotherapy. This area is in need of additional investigation.

As imaging techniques improve, asymptomatic small-volume VTE is being diagnosed more frequently in staging scans. There is little evidence to guide best management in this situation; for

\section{REFERENCES}

Agnelli G, Bolis G, Capussotti L, Scarpa RM, Tonelli F, Bonizzoni E, Moia M, Parazzini F, Rossi R, Sonaglia F, Valarani B, Bianchini C, Gussoni G (2006) A clinical outcome-based prospective study on venous thromboembolism after cancer surgery: the @RISTOS project. Ann Surg 243: $89-95$

Barlogie B, Desikan R, Eddlemon P, Spencer T, Zeldis J, Munshi N, Badros A, Zangari M, Anaissie E, Epstein J, Shaughnessy J, Ayers D, Spoon D, Tricot G (2001) Extended survival in advanced and refractory multiple myeloma after single-agent thalidomide: identification of prognostic factors in a phase 2 study of 169 patients. Blood 98: $492-494$

Blom JW, Doggen CJ, Osanto S, Rosendaal FR (2005) Malignancies, prothrombotic mutations, and the risk of venous thrombosis. JAMA 293: $715-722$

Blom JW, Osanto S, Rosendaal FR (2004) The risk of a venous thrombotic event in lung cancer patients: higher risk for adenocarcinoma than squamous cell carcinoma. J Thromb Haemost 2: 1760-1765

Bohlius J, Wilson J, Seidenfeld J, Piper M, Schwarzer G, Sandercock J, Trelle S, Weingart O, Bayliss S, Brunskill S, Djulbegovic B, Benett CL, Langensiepen S, Hyde C, Engert E (2006) Recombinant human erythropoietins and cancer patients: updated meta-analysis of 57 studies including 9353 patients. J Natl Cancer Inst 98: 708-714

Bouillard JB, Bouillaud S (1823) De l'Obliteration des veines et de son influence sur la formation des hydropisies partielles: consideration sur la hydropisies passive et general. Arch Gen Med 1: 188-204

Cavo M, Zamagni E, Cellini C, Tosi P, Cangini D, Cini M, Valdrè L, Palaretti G, Masini L, Tura S, Baccarani M (2002) Deep-vein thrombosis in patients with multiple myeloma receiving first-line thalidomide-dexamethasone therapy. Blood 100: 2272-2273

Colman RW (2006) Are hemostasis and thrombosis two sides of the same coin? J Exp Med 203: 493-495

Falanga A, Gordon SG (1985) Isolation and characterization of cancer procoagulant: a cysteine proteinase from malignant tissue. Biochemistry 24: $5558-5567$

Fernandez PM, Patierno SR, Rickles FR (2004) Tissue factor and fibrin in tumor angiogenesis. Semin Thromb Hemost 30: $31-44$

Hoffman R, Haim N, Brenner B (2001) Cancer and thrombosis revisited. Blood Rev 15: $61-67$

Howell A, Cuzick J, Baum M, Buzdar A, Dowsett M, Forbes JF, Hoctin-Boes G, Houghton J, Locker GY, Tobias JS (2005) Results of the ATAC (Arimidex, Tamoxifen, Alone or in Combination) trial after completion of 5 years' adjuvant treatment for breast cancer. Lancet 365: 60-62

Hurwitz H, Fehrenbacher L, Novotny W, Cartwright T, Hainsworth J, Heim W, Berlin J, Baron A, Griffing S, Holmgren E, Ferrera N, Fyfe G, Rogers B, Ross R, Kabbinavar F (2004) Bevacizumab plus irinotecan, fluorouracil, and leucovorin for metastatic colorectal cancer. $N$ Engl J Med 350: $2335-2342$

Kakkar AK, DeRuvo N, Chinswangwatanakul V, Tebbutt S, Williamson RC (1995) Extrinsic-pathway activation in cancer with high factor VIIa and tissue factor. Lancet 346: 1004-1005

Kakkar AK, Levine M, Pinedo HM, Wolff R, Wong J (2003) Venous thrombosis in cancer patients: insights from the FRONTLINE survey. Oncologist 8: $381-388$ example, whether these events should be treated - or if left untreated, there is little evidence to suggest that it affects outcome. This clearly warrants further investigation, although it may pose practical and ethical challenges in terms of study design.

\section{Conflict of interest}

KJ Pasi has received consulting fees from Bayer, Wyeth, Boehringer Ingelheim, Octapharma, and has also received lecture fees from Boehringer Ingelheim. S Noble has received grant support from Pfizer. All other related fees paid for consulting or lecture fees have been donated to charity.
Khorana AA, Francis CW, Culakova E, Fisher RI, Kuderer NM, Lyman GH (2006) Thromboembolism in hospitalized neutropenic cancer patients. J Clin Oncol 24: 484-490

Kirwan CC, Nath E, Byrne GJ, McCollum CN (2003) Prophylaxis for venous thromboembolism during treatment for cancer: questionnaire survey. BMA 327: $597-598$

Levitan N, Dowlati A, Remick SC, Tahsildar HI, Sivinski LD, Beyth R, Rimm AA (1999) Rates of initial and recurrent thromboembolic disease among patients with malignancy $v s$ those without malignancy. Risk analysis using Medicare claims data. Medicine (Baltimore) 78: $285-291$

Mielicki WP, Tenderenda M, Rutkowski P, Chojnowski K (1999) Activation of blood coagulation and the activity of cancer procoagulant (EC 3.4.22.26) in breast cancer patients. Cancer Lett 146: 61-66

Miller GJ, Bauer KA, Howarth DJ, Cooper JA, Humphries SE, Rosenberg RD (2004) Increased incidence of neoplasia of the digestive tract in men with persistent activation of the coagulant pathway. J Thromb Haemost 2: $2107-2114$

Monreal M, Raventos A, Lerma R, Ruiz J, Lafoz E, Alastrue A, Llamazares JF (1994) Pulmonary embolism in patients with upper extremity DVT associated to venous central lines - a prospective study. Thromb Haemost 72: $548-550$

Murchison JT, Wylie L, Stockton DL (2004) Excess risk of cancer in patients with primary venous thromboembolism: a national, population-based cohort study. Br J Cancer 91: 92-95

Nalluri SR, Chu D, Keresztes R, Zhu X, Wu S (2008) Risk of venous thromboembolism with the angiogenesis inhibitor bevacizumab in cancer patients: a meta-analysis. JAMA 300: 2277-2285

Oleksowicz L, Bhagwati N, DeLeon-Fernandez M (1999) Deficient activity of von Willebrand's factor-cleaving protease in patients with disseminated malignancies. Cancer Res 59: 2244-2250

Pengo V, Lensing AW, Prins MH, Marchiori A, Davidson BL, Tiozzo F, Albanese P, Biasiolo A, Pegoraro C, Iliceto S, Prandoni P (2004) Thromboembolic Pulmonary Hypertension Study Group. Incidence of chronic thromboembolic pulmonary hypertension after pulmonary embolism. N Engl J Med 350: 2257-2264

Prandoni P, Falanga A, Piccioli A (2005) Cancer and venous thromboembolism. Lancet Oncol 6: 401-410

Prandoni P, Lensing AW, Piccioli A, Bernardi E, Simioni P, Girolami B, Marchiori A, Sabbion P, Prins MH, Noventa F, Girolami A (2002) Recurrent venous thromboembolism and bleeding complications during anticoagulant treatment in patients with cancer and venous thrombosis. Blood 100: $3484-3488$

Prandoni P, Polistena P, Bernardi E, Cogo A, Casara D, Verlato F, Angelini F, Simioni P, Signorini GP, Benedetti L, Girolami A (1997a) Upperextremity deep vein thrombosis. Risk factors, diagnosis, and complications. Arch Intern Med 157: 57-62

Prandoni P, Villalta S, Bagatella P, Rossi L, Marchiori A, Piccoli A, Bernardi E, Girolami B, Simioni P, Girolam A (1997b) The clinical course of deepvein thrombosis. Prospective long-term follow-up of 528 symptomatic patients. Haematologica 82: $423-428$

Qi J, Kreutzer DL (1995) Fibrin activation of vascular endothelial cells. Induction of IL-8 expression. J Immunol 155: 867-876 
Rajkumar SV, Blood E, Vesole D, Fonseca R, Greipp PR (2006) Phase III clinical trial of thalidomide plus dexamethasone compared with dexamethasone alone in newly diagnosed multiple myeloma: a clinical trial coordinated by the Eastern Cooperative Oncology Group. J Clin Oncol 24: $431-436$

Rao LV, Pendurthi UR (2005) Tissue factor-factor VIIa signaling. Arterioscler Thromb Vasc Biol 25: 47-56

Rickles FR, Brenner B (2008) B Tissue factor and cancer. Semin Thromb Hemost 34: $143-145$

Saphner T, Tormey DC, Gray R (1991) Venous and arterial thrombosis in patients who received adjuvant therapy for breast cancer. J Clin Oncol 9: $286-294$

Shah MA, Ilson D, Kelsen DP (2005) Thromboembolic events in gastric cancer: high incidence in patients receiving irinotecan- and bevacizumab-based therapy. J Clin Oncol 23: 2574-2576
Stein PD, Beemath A, Meyers FA, Skaf E, Sanchez J, Olson RE (2006) Incidence of venous thromboembolism in patients hospitalized with cancer. Am J Med 119: 60-68

Trousseau A (1865) Phlegmasia alba dolens. Clinique Medicale de l'HotelDieu de Paris 3(94): 654-712

Verso M, Agnelli C (2003) Venous thromboembolism associated with longterm use of central venous catheters in cancer patients. J Clin Oncol 21: $3665-3675$

White RH, Chew HK, Zhou H, Parikh-Patel A, Harris D, Harvey D, Wun T (2005) Incidence of venous thromboembolism in the year before the diagnosis of cancer in 528,693 adults. Arch Intern Med 165: 1782-1787 Zangari M, Anaissie E, Barlogie B, Badros A, Desikan R, Gopal AV, Morris C, Toor A, Siegel E, Fink L, Tricot G (2001) Increased risk of deep-vein thrombosis in patients with multiple myeloma receiving thalidomide and chemotherapy. Blood 98: 1614-1615 